\title{
COST-EFFECTIVENESS ANALYSIS IN THE MANAGEMENT OF STROKE
}

\author{
GOPI B ${ }^{1}$, SUSHMITHA C ${ }^{1}$, NIKITHA KSV ${ }^{1}$, MONIKA M ${ }^{1}$, RAGHAVENDRA KUMAR GUNDA ${ }^{2 *}$, SATYANARAYANA V ${ }^{3}$, \\ SURESH KUMAR JN
}

${ }^{1}$ Department of Pharmacy Practice, Narasaraopeta Institute of Pharmaceutical Sciences, Narasaraopet, Guntur, Andhra Pradesh, India.

${ }^{2}$ Department of Pharmaceutics, Narasaraopeta Institute of Pharmaceutical Sciences, Narasaraopeta, Guntur, Andhra Pradesh, India.

${ }^{3}$ Department of Pharmacy Practice, Narasaraopeta Institute of Pharmaceutical Sciences, Narasaraopeta, Guntur, Andhra Pradesh, India.

Email: raghav.gunda@gmail.com

Received: 07 March 2017, Revised and Accepted: 13 April 2017

ABSTRACT

Objective: Stroke is one of the leading causes of death and disabilities worldwide. Cost-effectiveness analysis helps identify neglected opportunities by highlighting interventions that are relatively inexpensive, yet have the potential to reduce the disease burden substantially. In India, there are wide social and economic disparities. Socioeconomic environment influences occupation, lifestyle, and nutrition of social classes which in turn would influence the prevalence and profile of stroke. By reduction of delays in access to hospital and improving provision of affordable treatments can reduce morbidity and mortality in patients with stroke in India. This study is designed to measure and compare the costs (resources consumed) and consequences (clinical, economic, and humanistic) of pharmaceutical products and services and their impact on individuals, healthcare systems and society.

Methods: The purpose of this study is to analyze and conduct a cost-effectiveness analysis for the treatment of stroke in Guntur City Hospitals. The patients were treated either with aspirin or clopidogrel. The health outcomes were measured using Modified Rankin Scale, A prominent risk assessment scale for stroke. The pharmacoeconomic data were computed from the patient data collection forms.

Result: The incremental cost-effectiveness ratio of aspirin and clopidogrel were calculated to be Rs. 8046.2/year

Conclusion: The study concludes that aspirin has the increased socioeconomic impact when compared to Clopidogrel and we can see that the earlier therapy has supported discharge, home-based rehabilitation along with reduced hospital stay and hence preferable.

Keywords: Stroke, Pharmacoeconomics, Cost-effectiveness analysis, Aspirin, Clopidogrel, Incremental cost-effectiveness ratio.

(C) 2017 The Authors. Published by Innovare Academic Sciences Pvt Ltd. This is an open access article under the CC BY license (http://creativecommons. org/licenses/by/4. 0/) DOI: http://dx.doi.org/10.22159/ajpcr.2017.v10i7.18318

\section{INTRODUCTION}

Stroke is one of the leading causes of death and disabilities worldwide. In developing countries like Australia, United Kingdom, Canada, New Zealand, Korea, and Taiwan, there is a lot of economic impact on the stroke [1-6]. Recently, even in India, a lot of epidemiological data has been published on stroke [7-9]. Annually, about 16 million first-ever strokes occur in the world, causing a total of 5.7 million deaths [10]. As a consequence, stroke ranks as the second cause of death in the world population after ischemic heart disease (the third only if neoplastic diseases are considered as a group) [11]. About $85 \%$ of all stroke deaths are registered in low- and middle-income countries, which also account for $87 \%$ of the total losses due to stroke in terms of disability-adjusted life years calculated worldwide, in 72 million/year [12]. However, many people do not even know the economic burden the stroke condition gives to a patient. The health-care system in India is also different from other countries [13]. Even though Government hospitals are available, the private sector plays a major role in Health care. Health insurance covers only $10 \%$ of people and old people are not covered by health insurance policies [14]. The cost of treating a stroke patient can thus differ from other regions of the world

Pricing of medicines is a very sensitive issue for a developing country like India. The pricing causes direct effects on the patients as well as it determines the treatment compliance and also the availability of various brands in our country [15]. Pharmacoeconomics is a collection of descriptive and analytic techniques for evaluating Pharmaceutical interventions in health care system [16]. Pharmacoeconomics is a branch of health economics, which particularly focuses on the "costs and benefits of drug therapy" [17].
Pharmacoeconomic research identifies measures and compares:

- Costs (resources consumed) and

- Consequences (clinical, economic, and humanistic) of pharmaceutical products and services and their impact on individuals, health-care systems, and society.

Pharmacoeconomics would also result injudicious spending of resources available for healthcare [18]. Cost-effectiveness analysis is a method for assessing the gains in health relative to the costs of different health interventions. It is not the only criterion for deciding how to allocate resources, but it is an important one because it directly relates the financial and scientific implications of different interventions. Cost-effectiveness analysis helps identify neglected opportunities by highlighting interventions that are relatively inexpensive, yet have the potential to reduce the disease burden substantially. One of the advantages of using cost-effectiveness ratios is that they avoid some ethical dilemmas and analytical difficulties that arise when attempting cost-benefit analyses [19].

Socioeconomic environment influences occupation, lifestyle, and nutrition of social classes which in turn would influence the prevalence and profile of stroke. There are a number of studies on the cost treatment in patients with stroke from the developed countries very few from the developing countries. All expenditure incurred for the direct cost is met out-of-pocket by the patients. The treatment of stroke is expensive for a very large proportion of patients in developing countries like India.

Although the amount spent by the upper and the lower income patients are similar, the percentage of the income spent is higher among the low- 
income patients, due to their lower earning. By reduction of delays in access to hospital and improving provision of affordable treatments can reduce morbidity and mortality in patients with stroke in India. The era, in which high-tech care is generally favored, there is little likelihood that a less complex and cost-effective therapy will emerge as the preferred choice unless there are data to suggest the same. However, comparative cost-effectiveness analysis can lead to such insights. Hence, there is a need to carry out comparative cost-effective studies among patients receiving these therapies [20].

The aims and objectives of the study include:

- To evaluate the cost of management of stroke, its predictors, and the impact on social determinants of the family

- To analyze and conduct a cost-effectiveness analysis for the treatment of stroke in Guntur City Hospitals

- To evaluate the burden of cost in patients with stroke

- To audit all the pharmacotherapy, quality of life and cost-effectiveness by comparing different drug combinations.

\section{METHODS}

The study was a single-center, non-interventional observational study conducted over a period of 6 months, i.e. from August 2016 to January 2017 in the Department of Neurology, Guntur City Hospital, Kothapet, Guntur, and Andhra Pradesh. The data required for the study was collected from the patients at Guntur City Hospital, Guntur. A total of 100 patients from the Neurology Department were taken in the study. An equal number of patients, i.e., 50 each $(n=100)$ have been prescribed with aspirin and clopidogrel, respectively. The health outcomes were measured using Modified Rankin Scale, A prominent risk assessment scale for stroke. The pharmacoeconomic data were computed from the patient data collection forms. The data were statistically analyzed using SPSS (Statistical Package for Social Sciences) with version 24.0 (SPSS Inc., Bengaluru). All the continuous variables of normal distribution were presented in the form of mean with standard deviation. Statistically, the costeffectiveness was determined using the formula of incremental cost-effectiveness ratio (ICER) which is recommended by the World Health Organization

The ICER can be estimated by:

$$
\operatorname{ICER}=\frac{\left(C_{1}-C_{0}\right)}{\left(E_{1}-E_{0}\right)}
$$

Where $\mathrm{C}_{1}$ and $\mathrm{E}_{1}$ are the cost and effect in the intervention group and where $\mathrm{C}_{2}$ and $\mathrm{E}_{2}$ are the cost and effect in the control care group.

\section{Inclusion criteria}

- All adult inpatients of age $>55$ years admitted to neurology department

- Patients having past and present medical condition of ischemic stroke

- Patients with history of ischemic stroke and post-stroke disabilities

- Smokers and alcoholics

- Drug-induced stroke conditions (e. g. Use of oral contraceptives).

Exclusion criteria

- Pregnant women

- Patients with hemorrhagic stroke

- Patients age below 55 years.

\section{RESULTS AND DISCUSSION}

Health economics enacted the foundation for the branch of pharmacoeconomics for collating different health-care interventions, especially pharmaceuticals and generating meaningful cost-effective solutions for disease management. Policymakers increasingly use costeffectiveness analyses to inform decision-making on competing healthcare interventions. stroke is an important setting, which was a panic for economic evaluations because of the wide range of issues involved for the individual and society. It is one of the most expensive diseases as far as treatment is perturbed, as it generates higher health-care expenses than those produced by other disease. The present study enumerates to the current movement toward the extensive considerations in costeffectiveness analyses. The choice of aspirin over clopidogrel-yielded increased health benefits at a minimized cost. The efficacy significantly affects the total costs of the disease. We studied the cost (direct medical, nonmedical, and indirect) and socioeconomic impact of stroke in Guntur, India.

Domains related to physical, mental, emotional, and social functioning are included under a multidimensional concept called health-related quality of life. It goes beyond direct measures of population health, life expectancy, and causes of death, and focuses on the impact health status has on quality of life. Valuing health-related quality of life is not straightforward, and the use of QALYs requires caution. In the present article, we decided to base all QALY values on Modified Rankin Scale. Modified Rankin Scale is the most used tool for which we could find published values on all events and health states for input into our model.

In our study, the age group analysis shows that out of 100 patients, the age between 55 and 65 years of age having more number of patients, i.e., $74(74 \%)$ stroke patients and $20(20 \%)$ patients were from the age group of 66 to 75 years, and finally, $6(6 \%)$ patients were from the age group of 76 to 85 years of age. Age group of 55-65-year-old patients was mostly affected by stroke (Fig. 1).

Gender-wise distribution shows that out of 100 stroke patients' males were found to be $67(67 \%)$ and females were 33 (33\%) (Fig. 2). This shows that the males are highly affected by stroke.

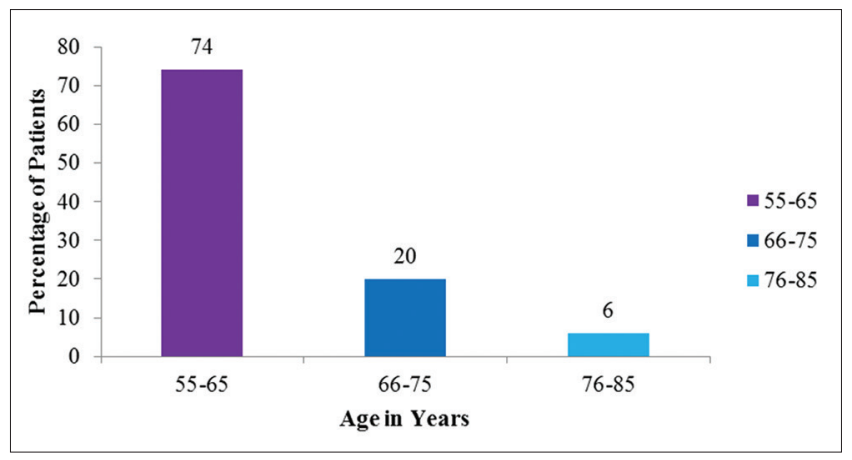

Fig. 1: Age-wise distribution of stroke patients $(n=100)$

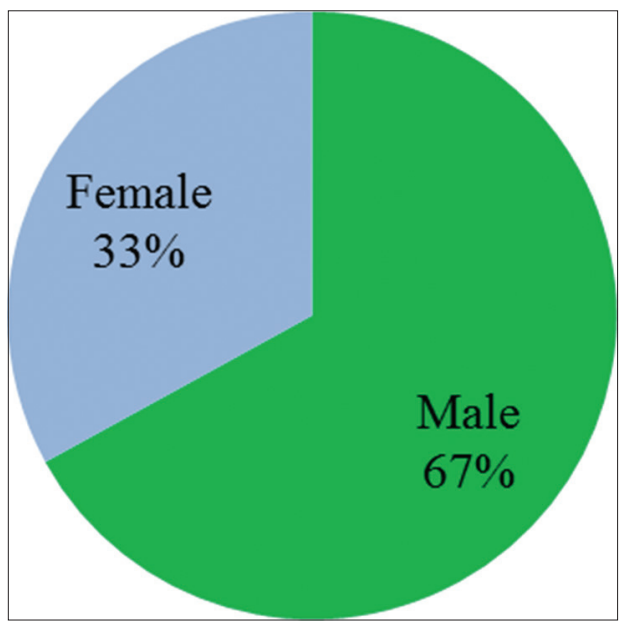

Fig. 2: Gender-wise distribution of stroke patients $(n=100)$ 
When evaluated for the risk factors of stroke majorly for the smoking status the analysis showed that out of 100 patients, 62 (62\%) were smokers and 38 (38\%) were non-smokers (Fig. 3). This reveals that Smokers are at a higher risk for the occurrence of stroke.

When evaluated for the alcohol consumption status, the analysis showed that out of 100 patients, 89 (89\%) were alcoholics, whereas $11(11 \%)$ were non-alcoholics (Fig. 4). This proves the fact that alcohol consumption causes higher blood pressure, thereby increasing the risk of stroke.

Comorbidities such as hypertension and diabetes mellitus have been shown to increase the risk of stroke. In our study, out of 100 patients, 39 (39\%) patients have hypertension, $5(5 \%)$ patients have diabetes mellitus, 32 (32\%) patients have both hypertension and diabetes mellitus, and $24(24 \%)$ patients have no recorded comorbidities (Fig. 5). Most of the patients either have hypertension or a treacherous combination of hypertension and diabetes mellitus.

The evaluation of quality of life of all the stroke patients receiving either the aspirin or the clopidogrel therapy shows that the sum of Modified Rankin Scale scores in aspirin is 95 and the sum of Modified Rankin Scale scores in clopidogrel is 115 (Fig. 6). The low Modified Rankin Scale score in aspirin denotes the increased quality of life in the patients receiving Aspirin. The high-Modified Rankin Scale in clopidogrel indicates the decreased quality of Life in the patients receiving clopidogrel. Compared to clopidogrel, aspirin shows good health-related outcomes.

Based on Table 1, the students paired t-test was used to compare the cost difference between aspirin and clopidogrel. From the students paired t-test, we concluded that aspirin is more cost-effective than clopidogrel.

\section{ICER=Rs. 8046.2}

The ICER can be calculated by dividing the difference in costs of control group and intervention groups with the difference in the effects caused by the control group and the interventional group. The total costs of the control group, i.e., patients' prescribed with aspirin are evaluated to be Rs. 388219. The total costs of the interventional group i.e., patients prescribed with Clopidogrel are evaluated to be Rs. 549143. The sum of Modified Rankin Scale scores of the control group is found to be 95 whereas the sum of Modified Rankin Scale scores of the interventional group is found to be 115 . The ICER was calculated to be Rs. 8046.2 (Table 2). Low ICER than the threshold determines the cost-effectiveness of the drug therapy.

This analysis shows that Aspirin is more cost-effective than Clopidogrel in the treatment of stroke also offering a favorable adverse effect profile and quality of life in comparison to the latter. Stroke, given its chronicity and associated morbidity and mortality, constitutes a significant disease burden to the society, both in terms of the health-related repercussions as well as financial costs incurred due to morbidity and cumulative cost of drug therapy. Hence, it is important to administer drugs that are costeffective and have minimal side effects. This is particularly important in a developing country like India, where the accretive cost of the longterm therapy is often a significant deterrent to patient compliance. The results of this study contribute toward decision-making involved in formulary management and by clinicians treating the patients with stroke.

\section{CONCLUSION}

The study concludes that the pharmacoeconomic evaluation of stoke is essential to obtain optimal therapy at lowest price and which medication helps the poor and middle-class patients to give appropriate health-care service. The cost driving factors in case of aspirin were found to be manageable income, better outcomes, and reduced length

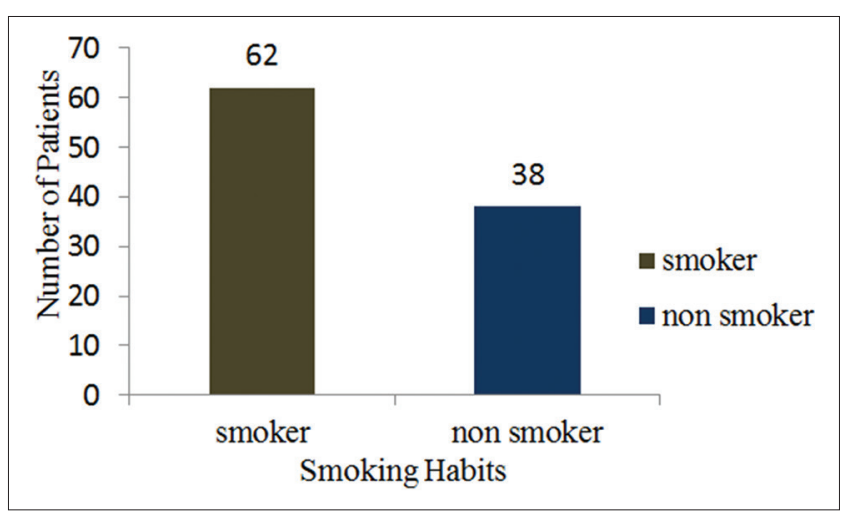

Fig. 3: Details on smoking status $(n=100)$

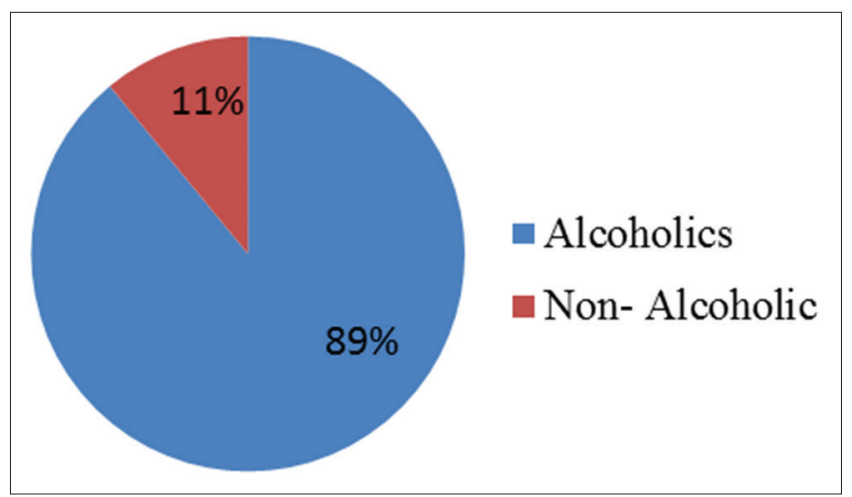

Fig. 4: Details on alcohol consumption status $(n=100)$

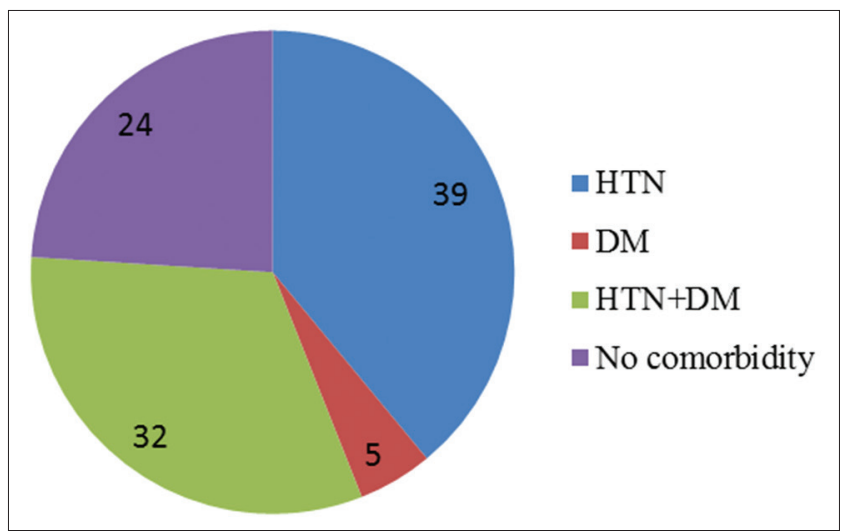

Fig. 5: Details on comorbidities/associated conditions that led to stroke

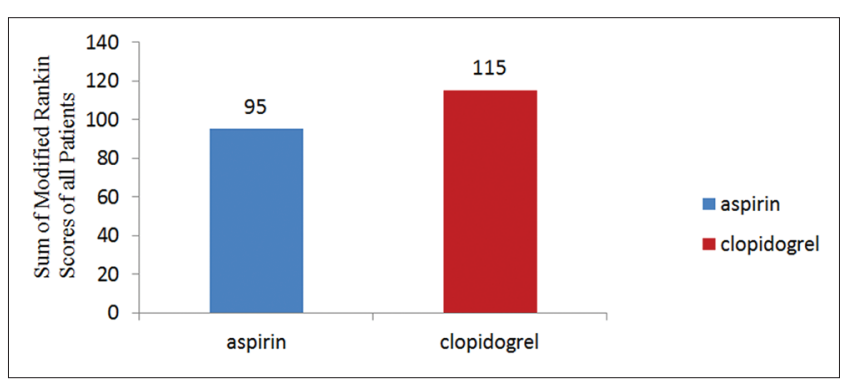

Fig. 6: Quality of life evaluation of stroke patients on aspirin/ clopidogrel therapy 
Table 1: Summary of distribution of cost analysis of stroke patients

\begin{tabular}{|c|c|c|c|c|c|c|c|c|}
\hline \multirow[t]{2}{*}{ Cost analysis of aspirin (A) and clopidogrel (C) } & \multicolumn{2}{|c|}{ Minimum } & \multicolumn{2}{|c|}{ Maximum } & \multicolumn{2}{|l|}{ Mean } & \multicolumn{2}{|l|}{ SD } \\
\hline & A & C & A & $\mathbf{C}$ & A & C & A & $\mathbf{C}$ \\
\hline Total medicine cost & 1 & 45 & 16 & 265 & 5.36 & 87.72 & 3.31 & 39.69 \\
\hline Hospital costs & 1400 & 2100 & 9100 & 14000 & 3284 & 4648 & 1591.47 & 2018.71 \\
\hline Direct costs & 4953 & 5650 & 12962 & 18880 & 7593.36 & 10005.6 & 1850.19 & 2688.67 \\
\hline Physiotherapy costs & 300 & 600 & 600 & 1200 & 454.54 & 856 & 102.59 & 220 \\
\hline FPC costs & 200 & 200 & 300 & 600 & 244 & 376 & 35.91 & 164.82 \\
\hline Indirect costs & 200 & 200 & 850 & 1800 & 543 & 804 & 232.99 & 541.33 \\
\hline Total costs & 5153 & 6250 & 13162 & 19480 & 7764.38 & 10982.8 & 1769.20 & 2663.23 \\
\hline
\end{tabular}

p value is calculated as 0.01 and is significant, SD: Standard deviation, FPC: Further physician consultations

Table 2: Calculation of ICER

\begin{tabular}{lll}
\hline Drug therapy & Total costs (INR) & Total effects \\
\hline Aspirin & 388219 & 95 \\
Clopidogrel & 549143 & 115 \\
\hline
\end{tabular}

ICER: Incremental cost-effectiveness ratio

of hospital stay. In contrast, the clopidogrel cost-driving factors were higher income, poor outcomes, and increased length of hospital stay. Aspirin has the increased socioeconomic impact when compared to clopidogrel, and we can see that the earlier therapy has supported discharge, home-based rehabilitation along with reduced hospital stay.

\section{REFERENCES}

1. Dewey HM, Thrift AG, Mihalopoulos C, Carter R, Macdonell RA, McNeil JJ, et al. Cost of stroke in Australia from a societal perspective: Results from the North East Melbourne Stroke Incidence Study (NEMESIS). Stroke 2001;32(10):2409-16.

2. Saka O, McGuire A, Wolfe C. Cost of stroke in the United Kingdom. Age Ageing 2009;38(1):27-32.

3. Goeree R, Blackhouse G, Petrovic R, Salama S. Cost of stroke in Canada: A 1year prospective study. J Med Econ 2005;8:147-67.

4. Scott WG, Scott H. Ischaemic stroke in New Zealand: An economic study. N Z Med J 1994;107(989):443-6.

5. Lim SJ, Kim HJ, Nam CM, Chang HS, Jang YH, Kim S, et al. Socioeconomic costs of stroke in Korea: Estimated from the Korea national health insurance claims database. J Prev Med Public Health 2009; 42(4):251-60.

6. Chang $\mathrm{KC}$, Tseng MC. Costs of acute care of first-ever ischemic stroke in Taiwan. Stroke 2003;34(11):e219-21.

7. Das SK, Banerjee TK, Biswas A, Roy T, Raut DK, Mukherjee CS, et al. A prospective community-based study of stroke in Kolkata, India. Stroke 2007;38(3):906-10.
8. Sridharan SE, Unnikrishnan JP, Sukumaran S, Sylaja PN, Nayak SD, Sarma PS, et al. Incidence, types, risk factors, and outcome of stroke in a developing country: The Trivandrum Stroke Registry. Stroke 2009;40(4):1212-8.

9. Dalal PM, Malik S, Bhattacharjee M, Trivedi ND, Vairale J, Bhat P, et al. Population-based stroke survey in Mumbai, India: Incidence and 28-day case fatality. Neuroepidemiology 2008;31(4):254-61.

10. Strong K, Mathers C, Bonita R. Preventing stroke: Saving lives around the world. Lancet Neurol 2007;6(2):182-7.

11. Di Carlo A. Human and economic burden of stroke. Age Ageing 2009;38(1):4-5.

12. Lopez AD, Mathers CD, Ezzati M, Jamison DT, Murray CJ. Global and regional burden of disease and risk factors, 2001: Systematic analysis of population health data. Lancet 2006;367(9524):1747-57.

13. Felicissimo T, Mosegui GB, Vianna CM, Araujo RL, Rodrigues MP, Valle PM, et al. Cost effectiveness analysis of trastuzumab in the treatment of metastatic breast cancer. Int $\mathrm{J}$ Pharm Pharm Sci 2015;7(4):307-12

14. Balarajan Y, Selvaraj S, Subramanian SV. Health care and equity in India. Lancet 2011;377(9764):505-15.

15. Atal S, Atal S, Deshmankar B, Nawaz SA. Cost analysis of commonly used drugs under price control in India: Assessing the effect of drug price control order on brand price variation. Int J Pharm Pharm Sci 2016;8(4):315-21

16. Pashos CL, Klein EG, Wanke LA. ISPOR Lexicon. $1^{\text {st }}$ ed. Princeton: International Society for Pharmacoeconomics and Outcomes Research; 1998.

17. Ahuja J, Gupta M, Gupta AK, Kohli K. Pharmacoeconomics. Natl Med J India 2004;17(2):80-3

18. Panaskar AN, Mane BD. Pharmacoeconomics: Need for introduction in Indian health care. Int J Curr Pharm Sci 2014;1(2):149-52.

19. Jamison DT, Breman JG, Measham AR, Alleyne G, Claeson M, Evans DB, et al., editors. Disease Control Priorities in Developing Countries. Washington, DC: The International Bank for Reconstruction and Development/The World Bank; 2006.

20. Mushlin AI, Ghomrawi H. Health care reform and the need for comparative-effectiveness research. N Engl J Med 2010;362(3):e6. 